\title{
Quality of Life Among Breast Cancer Patients Attending Hawassa University Comprehensive Specialized Hospital Cancer Treatment Center
}

This article was published in the following Dove Press journal: Breast Cancer: Targets and Therapy

\author{
Dubale Dulla Koboto' \\ Bedilu Deribe ${ }^{2}$ \\ Achamyelesh Gebretsadik ${ }^{3}$ \\ Girma Ababi ${ }^{4}$ \\ Netsanet Bogale ${ }^{4}$ \\ Dereje Geleta (iD) 3 \\ Lalisa Gemechu ${ }^{5}$ \\ Kurabachew Mengistu ${ }^{4}$ \\ 'Department of Midwifery, College of \\ Medicine and Health Sciences, Hawassa \\ University, Hawassa, SNNPR, Ethiopia; \\ ${ }^{2}$ School of Nursing, College of Medicine \\ and Health Sciences, Hawassa University, \\ Hawassa, SNNPR, Ethiopia; ${ }^{3}$ School of \\ Public Health, College of Medicine and \\ Health Sciences, Hawassa University, \\ Hawassa, SNNPR, Ethiopia; ${ }^{4}$ Fuculty of \\ Medicine, College of Medicine and Health \\ Sciences, Hawassa University, Hawassa, \\ SNNPR, Ethiopia; ${ }^{5}$ Department of \\ Environmental Health, College of \\ Medicine and Health Sciences, Hawassa \\ University, Hawassa, SNNPR, Ethiopia
}

Correspondence: Dubale Dulla Koboto Hawassa University, CMHS, Department of Midwifery, Hawassa, SNNPR, Ethiopia Tel +251913850895

Email dzmhkb2012@gmail.com
Background: Breast cancer affects the overall quality of life (QOL) among its survivors. Limited evidence is available about the QOL among cases. Therefore, this study was intended to assess the quality of life of breast cancer patients attending the cancer treatment center at Hawassa University Comprehensive Specialized Hospital, Hawassa, southern Ethiopia.

Methods: An institution-based cross-sectional study was conducted among breast cancer patients attending cancer treatment at the Hawassa University Comprehensive Specialized Hospital between April and June, 2019. All breast cancer patients attending treatment the center were included in the study by universal sampling. Data were collected using a structured questionnaire containing demographic data, patient clinical factors and Quality of Life Instrument (WHOQOL)-BREF version 3.0. The collected data were entered into EpiData software version 3.1 and analyzed using SPSS Version 20.0. Descriptive statistics were presented in tables.

Results: A total of 259 respondents with a mean age of (SD) 44.89 (12.56) participated in study. The mean score of overall global health scale was $75.3(\mathrm{SD} \pm 17.1)$ with the mean health satisfaction was 12.43 ( $\mathrm{SD} \pm 3.98$ ). The highest mean score was observed in environmental domain, 93.31 ( $\mathrm{SD} \pm 19.76$ ), despite social domain being very low, 36.69 ( $\mathrm{SD} \pm 7.62$ ). Most of the participants were highly satisfied with the health care service that was provided, with a mean score of $16.1(\mathrm{SD} \pm 3.1)$. In contrast, the majority of study participants were disappointed with the need for any medical treatment, body appearance, luxurious activities, and sexual life, with mean scores of $8.93(\mathrm{SD} \pm 3.68), 8.74(\mathrm{SD} \pm 4.26), 9.1(\mathrm{SD} \pm 4.22)$, and 8.1 ( $\mathrm{SD} \pm 4.14)$, respectively.

Conclusion: Breast cancer patients in southern Ethiopia suffered from poor social and psychological support that, in turn, highly affected their life value. Therefore, due attention should be given to enhance social and psychological support for breast cancer patients as a whole.

Keywords: breast cancer, quality of life, domains of QOL, Hawassa

\section{Background}

Globally, 17.2 million cancer cases and 8.9 million deaths occurred in 2016 with cases increased by $28 \%$ from 2006 to 2016 . Breast cancer is the most common cancer among women leading to 1.7 million cases and it is the leading cause of cancer deaths among women with 535,000 deaths per year and 14.9 million disability-adjusted life-years ( DALYs ). ${ }^{1}$ Many women who live in low-income and middle-income countries suffer from breast cancer, a largely preventable tragedy for hundreds of thousands of women and their families every year. ${ }^{2}$ 
Studies identified that breast cancer is the leading problem (31.5\% of all registered cancer cases) for women in Ethiopia because they often ignore indicators of its precursors and usually look for treatment only when symptoms occur. $^{3-5}$ Besides, they often access nonhospital primarily, individual physician/a private hospital setting, traditional and religious healers in the first instance and are resistant towards modern treatment, related to their knowledge of the disease and its treatment options, family pressure and preferences ${ }^{6}$ for seeking complementary and alternative medicine. ${ }^{7}$ Patients definitely reach a worse stage before presenting at the referral hospital. ${ }^{6}$ Women with breast cancer face a variety of unique treatment and psychosocial issues at diagnosis and follow-up. Increasing attention to their unique issues may improve outcomes of care, quality of life (QOL) and survival for this vulnerable population. Breast cancer therefore, affects the overall quality of life as well as their survival. ${ }^{8}$

Health-related QOL is a multidimensional, subjective and dynamic concept with four main domains: physical, psychological, social, and environmental functioning. ${ }^{9}$ Researchers measure it by identifying patient's perception about his/her treatment and illness that constitutes relevant and alternative management. ${ }^{7,10}$ Hence, it had been very difficult to measure QOL of cancer survivors. Many patients need some sort of intervention for their cancer and found it difficult to accept the concept of QOL, but some patients would stop treatment that they opted for initially if it was affecting their QOL. ${ }^{11-13}$ Ensuring good QOL of breast cancer patients is deemed as an important outcome of treatment and for making informed clinical and health policy decisions on the care of these patients. ${ }^{14}$

However, the Ethiopian Federal Minster of Health had taken up its accountability to ensure a better quality of life for people living with cancer. ${ }^{15}$ As cancer incidence is expected to increase in the future, detailed knowledge on the burden of cancer or level of QOL is needed for allocation of resources for cancer prevention, early diagnosis, and curative and palliative care. ${ }^{1}$ Management of breast cancer patients extended to regional hospitals in Ethiopia and there were considerable improvements in the overall approach to the disease by encouraging a positive approach, even in poor resource environments. ${ }^{16}$ However, more information is needed on QOL of breast cancer patients to ascertain the sort of services that are required to improve their QOL; no specific study was conducted in our study area in this regard. Therefore this study was intended to identify the QOL among breast cancer patients in Hawassa University Comprehensive Specialized Hospital Cancer Treatment Center.

\section{Method and Materials}

The institutional-based cross-sectional study was conducted among breast cancer patients attending the cancer treatment center in Hawassa University Comprehensive Specialized Hospital (HUCSH) between April and June, 2019. HUCSH is one of the teaching and referral hospitals providing cancer treatment for the southern nation's nationalities and peoples of Ethiopia and is under Hawassa University. The hospital was established in 1998 GC and accommodates about 400 beds for inpatient service of which 316 are functional. A total of 120,949 cases attended this hospital during the 2018/19 financial year. Of these, 12,891 were admitted to an emergency ward. Nearly 1200 cases were registered in the oncology ward. All patients diagnosed with breast cancer and attending for treatment at the Hawassa University Comprehensive Specialized Hospital were included in the study. While those with previous neoplastic disease were excluded.

\section{Sampling Procedure and Sample Size}

All eligible patients who attended the cancer treatment center in the hospital during the study period were enrolled into the study. All breast cancer patients coming to the treatment center within the study period were included in this study. Currently 259 breast cancer patients were involved in the study following their management in this hospital.

\section{Data Collection Tools and Procedure}

Data was collected by using a structured questionnaire, containing demographic data, patient clinical factors that included socioeconomic characteristics:- age, sex marital status, place of residence, educational status, occupation, monthly income, gravidity and parity, clinical features of comorbidity, blood pressure, duration of illness after diagnosis, type management including surgeries and Quality of Life Assement Instrument (WHOQOL-BREF version 3.0) which has a 26-item ordinal scale that measures the QOL of a breast cancer patient by focusing on four domains (physical, psychological, social, and environmental). ${ }^{17,18}$ The data collection was accomplished by four data collectors who have a first degree in nursing/midwifery. All the data collectors and the supervisor had been adequately trained in the purpose of 
the study, patient recruitment process and data collection techniques in two days.

\section{Data Management and Analysis}

The collected data were entered into a computer on an ongoing basis using the software EpiData version 3.1. To minimize data entry errors, the data was double-entered by two independent data entry clerks. After all data are double-entered into EpiData, the two independent datasets were compared using the "validate duplicate files" facility of EpiData and discordant entries were corrected by comparing the entered data with the hard-copy questionnaire. The data was then exported to IBM SPSS version 20 (IBM Corporation, Armonk, NY, USA) for further processing and analysis. Before data analysis the data were explored for outliers and to see normal distribution. Means below the average value were classified as poor and those values greater than the mean were considered as good. In addition, data analysis consisted of descriptive statistics. Variable of the study including frequencies of demographic and clinical variables as well the QOL items were computed. One-sample $t$ test was used to compare means and identify $P$-values. The finding of study presented by mean, median scores and SD of the QOL items.

The minimum and maximum values of four identified domains were calculated using the guide of WHOQOLBREF. According the guideline, each domain includes a specified number of questions of the WHOQOL-BREF questionnaire. Physical health domain has seven; psychological domain incorporate has six; social domain has three and environmental domain includes eight questions. The first two questions have been taken as indicators of overall quality of QOL, so that, taken independently. It is stated that as the percent of a given domain increases, the quality/satisfaction rate also increases. ${ }^{17}$

\section{Ethical Consideration}

This study was conducted in accordance with the Declaration of Helsinki. It was approved and verbal informed consent was acceptable by the Institutional Review Board of the College of Medicine and Health Sciences of Hawassa University with official letter with reference number of IRB/027/11; and data collection tool for quality of life measurement adapted from WHO (WHOQOL-BREF) that was approved by ID: 337333.

\section{Results}

Sociodemographic Characteristics of Study Participants

A total of 259 survivors of breast cancer participated in the study. As provided in Table 1, the age of respondents ranged from 24 to 85 years with a mean (SD) of 44.89 (12.56). Of all participants, $96.5 \%$ were female; $74.9 \%$ were married; $52.1 \%$ had no formal education; $50.6 \%$ were housewives; $84.2 \%$ stayed active after the disease was identified until the study period; their average monthly income was 3868.78ETB (\$96.72) with a range of 400-

Table I Sociodemographic Characteristics of Study Population

\begin{tabular}{|c|c|c|}
\hline Sociodemographic Variables & Frequency $N=259$ & Percent \\
\hline \multicolumn{3}{|l|}{ Age } \\
\hline$<50$ & 189 & 73 \\
\hline$\geq 50$ & 70 & 23 \\
\hline \multicolumn{3}{|l|}{ Sex } \\
\hline Female & 250 & 96.5 \\
\hline Male & 9 & 3.5 \\
\hline \multicolumn{3}{|l|}{ Marital status } \\
\hline Single & 6 & 2.3 \\
\hline Married & 194 & 74.9 \\
\hline Separated & 7 & 2.7 \\
\hline Divorced & 28 & 10.8 \\
\hline Widowed & 24 & 9.3 \\
\hline \multicolumn{3}{|l|}{ Education } \\
\hline No formal education & 135 & 52.1 \\
\hline Elementary & 31 & 12 \\
\hline Secondary & 27 & 10.4 \\
\hline Tertiary & 66 & 25.5 \\
\hline \multicolumn{3}{|l|}{ Employment before disease } \\
\hline Housewife & $|3|$ & 50.6 \\
\hline Daily worker & 7 & 2.7 \\
\hline Merchant & 25 & 9.6 \\
\hline Employed & 96 & 37.1 \\
\hline \multicolumn{3}{|l|}{ Employment after disease } \\
\hline Actively employed & 218 & 84.2 \\
\hline Homemaker/retired & 41 & 15.8 \\
\hline \multicolumn{3}{|l|}{ Monthly income } \\
\hline$<$ I500ETB $(<\$ 37.5)$ & 133 & 51.4 \\
\hline I500-4500ETB (\$37.5- \$1 | 2.5) & 65 & 25.1 \\
\hline$>4500 \mathrm{ETB}(>\$ 1 \mid 2.5)$ & 61 & 23.6 \\
\hline \multicolumn{3}{|l|}{ Residence } \\
\hline Rural & 115 & 44.4 \\
\hline Suburban & 52 & 20.1 \\
\hline Urban & 92 & 35.5 \\
\hline
\end{tabular}


16000ETB (\$10-400); $84.2 \%$ were actively engaged in their daily activities and nearly half (44.4\%) of respondents reside in a rural community.

\section{Frequency of Obstetric Variables and Chronic Diseases Among the Respondents}

Table 2 illustrates the obstetric characteristics of respondents. Among participants 250 (96.5\%) of the respondents were female, of which $4.4 \%$ reported that they never get pregnant. Besides, $15.8 \%$ stated they practiced abortion and $24.8 \%$ undergone abdominal surgery. However, the majority (45.2\%) of participants had given birth to four or more children.

In addition comorbidity of participants is assessed. Among all participants, 61 (23.5\%) had comorbidities of which hypertension accounts the majority (73.7\%) of chronic diseases facing the participants (Table 3).

\section{Clinical Characteristics of Study Population}

More than half of the respondents (56\%) reported that they were diagnosed within six months after the onset of symptoms of breast cancer. About $91.5 \%$ of respondents had sought treatment during the six months postdiagnosis of breast cancer. The majority of the patients $(79.6 \%)$ were diagnosed at stages III and IV while only $0.4 \%$ patients

Table 2 Frequency of Obstetric Variables of Study Population

\begin{tabular}{|c|l|l|}
\hline Obstetric Variables & Frequency & Percent \\
\hline Gravidity & & \\
0 & 11 & 4.4 \\
I-3 & 105 & 42 \\
$4-7$ & 99 & 39.6 \\
$>7$ & 35 & 14 \\
\hline Parity & & \\
0 & 13 & 5.2 \\
$<3$ & 124 & 49.6 \\
$4-7$ & 92 & 36.8 \\
$>7$ & 21 & 8.4 \\
\hline Abortion & & \\
No & 218 & 84.2 \\
$\leq 2$ & 30 & 15 \\
$\leq 3$ & 2 & 0.8 \\
\hline Any obstetric surgery & & \\
Yes & 72 & 27.8 \\
No & 187 & 72.2 \\
\hline
\end{tabular}

Table 3 Presence of Chronic Diseases Among Study Population

\begin{tabular}{|l|l|l|}
\hline Chronic Disease & Frequency & Percent \\
\hline Diabetic & & \\
Present & 11 & 4.2 \\
Absent & 248 & 95.8 \\
\hline Hypertension & & \\
Present & 45 & 17.4 \\
Absent & 214 & 82.6 \\
\hline Asthma & & \\
Present & 5 & 1.9 \\
Absent & 254 & 98.1 \\
\hline
\end{tabular}

were diagnosed at stage 0. Among all participants $74.1 \%$ had undergone breast surgery of which nearly two-third of the patients $(65.6 \%)$ underwent mastectomy and the remainder breast conserving surgery. The majority of the respondents $(89.2 \%)$ had received chemotherapy and $29.5 \%$ had received radiography. Only $3.5 \%$ had previous history of breast cancer. Table 4 summarizes the clinical characteristics of the sample population.

\section{Reasons for Delay Before Diagnosis Among Study Population}

However, the duration of delays in diagnosis varies among participants for different reasons. As presented in Table 5, three-quarters of the participants $(73 \%)$ reported that they delayed seeking diagnosis due to feeling no pain, two-thirds of the participants $(62.7 \%)$ described that they were seeking cultural and/or religious treatment, even though they felt pain. Nearly two-fifths $(60.6 \%)$ of respondents said that they did not seek medical diagnosis because of lack of money.

\section{Quality of Life Among Respondents}

Table 6 represents the mean score and percent of the QOL scales of WHOQOL-BREF Breast Cancer-specific-BR23 questionnaires among the respondents (20). Mean score of overall global health scale was $75.3(\mathrm{SD} \pm 17.1)$ and their mean health satisfaction was estimated to be 12.43 (SD \pm 3.98 ). Among four domains of WHOQOL-BREF the highest mean score was observed for environmental domain: 93.31 ( $\mathrm{SD} \pm 19.76$ ), followed by physical health domain: 88.26 ( $\mathrm{SD} \pm 21.61)$ whereas, psychological domain: 68.2 ( $\mathrm{SD} \pm 19.07$ ), and social domain: 36.69 ( $\mathrm{SD} \pm 7.62$ ). Regarding individual questions, most of participants were highly satisfied by the health care service provided with a mean score of $16.1(\mathrm{SD} \pm 3.1)$. In contrast, the majority of 
Table 4 Clinical Characteristics of Study Population

\begin{tabular}{|c|c|c|}
\hline Clinical Characteristics & Frequency & Percent \\
\hline \multicolumn{3}{|l|}{ Delays before diagnosis } \\
\hline$<6$ months & 154 & 56 \\
\hline 6-24 months & 96 & 37.1 \\
\hline$>24$ months & 18 & 6.9 \\
\hline \multicolumn{3}{|l|}{ Delays before treatment } \\
\hline$<6$ months & 237 & 91.5 \\
\hline 6-24 months & 21 & 8.1 \\
\hline$>24$ months & 1 & 0.4 \\
\hline \multicolumn{3}{|l|}{ Stages at diagnosis } \\
\hline Stage 0 & 1 & 0.4 \\
\hline Stage I & 7 & 2.7 \\
\hline Stage II & 45 & 17.4 \\
\hline Stage III & 104 & 40.2 \\
\hline Stage IV & 102 & 39.4 \\
\hline \multicolumn{3}{|l|}{ Type of breast surgery done (192) } \\
\hline Breast conserving surgery & 60 & 31.3 \\
\hline Mastectomy & 126 & 65.6 \\
\hline Breast reconstructive surgery & 6 & 3.1 \\
\hline \multicolumn{3}{|l|}{ Radiotherapy done (259) } \\
\hline Yes & 53 & 20.5 \\
\hline No & 206 & 79.5 \\
\hline \multicolumn{3}{|l|}{ Chemotherapy } \\
\hline Yes & 231 & 89.2 \\
\hline No & 28 & 10.8 \\
\hline \multicolumn{3}{|l|}{ Chemotherapy started (23I) } \\
\hline Before surgery & 64 & 27.7 \\
\hline After surgery & 167 & 72.3 \\
\hline \multicolumn{3}{|l|}{ Previous history of breast cancer } \\
\hline Present & 9 & 3.5 \\
\hline Absent & 250 & 96.5 \\
\hline \multicolumn{3}{|l|}{ Duration of recurrence (9) } \\
\hline$<5$ years & 3 & 33.3 \\
\hline $5-10$ years & 4 & 44.4 \\
\hline$>10$ years & 2 & 22.2 \\
\hline
\end{tabular}

study participants were disappointed with their need for any medical treatment, feelings of their body appearance, enjoying luxurious activities and satisfaction with their sex life were predicted as very poor $8.93(\mathrm{SD} \pm 3.68), 8.74(\mathrm{SD} \pm 4.26)$, $9.1(\mathrm{SD} \pm 4.22)$, and $8.1(\mathrm{SD} \pm 4.14)$ accordingly, because these values were very low in relation to the mean value.

\section{Discussion}

In this study, mean age (SD) of participants was 44.89 (12.56). The study found that participants were highly
Table 5 Reasons for Delay Before Diagnosis of Study Population

\begin{tabular}{|l|l|l|}
\hline Reasons for Delay Before Diagnosis & Frequency & Percent \\
\hline $\begin{array}{l}\text { Painless symptoms } \\
\text { Yes }\end{array}$ & 189 & 73 \\
No & 70 & 27 \\
\hline Seeking cultural treatment & & \\
Yes & 96 & 37.1 \\
No & 163 & 62.9 \\
\hline Seeking religious treatment & & \\
Yes & 66 & 25.5 \\
No & 193 & 74.5 \\
\hline Lack of money & & \\
Yes & 102 & 39.4 \\
No & 157 & 60.6 \\
\hline Do not know where to go & & \\
Yes & 20 & 7.7 \\
No & 239 & 92.3 \\
\hline Other reasons & & \\
Yes & 2 & 0.8 \\
No & 257 & 99.2 \\
\hline
\end{tabular}

satisfied with health care services that they received with a mean score of $16.1(\mathrm{SD} \pm 3.1)$. However, most of them were disappointed with the need for any medical treatment, body appearance, luxurious activities and sex life. Diagnosis at late stages and delayed diagnosis were realized in most (45.6\%) of the breast cancer patients, ${ }^{19}$ which are lower than the findings of this study. However, in studies conducted in northern Ethiopia about $85 \%$ of cases were diagnosed at stages III and IV $^{20}$ consistent with our findings which reported that almost $80 \%$ of breast cancer patients diagnosed at stages III and IV, could in turn affect the treatment outcome. In this study only $6.9 \%$ of participants came to seek care after 24 months of symptoms but in one Malaysian study, $18.8 \%$ breast cancer patients were diagnosed after 24 months of onset of cancer symptoms. ${ }^{19}$

However, the duration of delays for diagnosis varies among participants because of different reasons. Seventythree percent of the participants reported that they delayed seeking diagnosis due to feeling no pain which is in line with finding of study conducted on breast cancer in an Ethiopian population, Addis Ababa, ${ }^{21} 62.7 \%$ described that they were seeking cultural and/or religious treatment, even though they felt pain. Nearly two-fifths of respondents said that they did not seek medical diagnosis due to 
Table 6 Mean and Median Score of WHOQOL-BREF Cancer Breast Cancer-Specific-BR23 Questionnaires Among Study Population

\begin{tabular}{|c|c|c|c|c|c|}
\hline Variables $(\mathrm{N}=\mathbf{2 5 9})$ & Min & Max & Mean & SD & $P$-value \\
\hline Rate your quality of life & 1 & 5 & 12.23 & 4.29 & $<0.00$ \\
\hline $\begin{array}{l}\text { Are you satisfied with your } \\
\text { health }\end{array}$ & 1 & 5 & 12.43 & 3.98 & $<0.00$ \\
\hline $\begin{array}{l}\text { Does pain prevent you } \\
\text { from doing things }\end{array}$ & 1 & 5 & 10.19 & 3.92 & $<0.00$ \\
\hline $\begin{array}{l}\text { Do you need any medical } \\
\text { treatment }\end{array}$ & 1 & 5 & 8.93 & 3.68 & $<0.00$ \\
\hline Do you enjoy life & 1 & 5 & 11.20 & 4.19 & $<0.00$ \\
\hline $\begin{array}{l}\text { Do you feel life is } \\
\text { meaningful for you }\end{array}$ & I & 5 & 12.77 & 4.06 & $<0.00$ \\
\hline $\begin{array}{l}\text { Are you able to } \\
\text { concentrate }\end{array}$ & 1 & 5 & $\mid 2.31$ & 3.75 & $<0.00$ \\
\hline Do you feel safe in daily life & 1 & 5 & 12.11 & 3.72 & $<0.00$ \\
\hline $\begin{array}{l}\text { Is physical environment safe } \\
\text { for you }\end{array}$ & I & 5 & 11.71 & 3.67 & $<0.00$ \\
\hline Do you have enough energy & 1 & 5 & 11.63 & 3.97 & $<0.00$ \\
\hline $\begin{array}{l}\text { Do you accept your body } \\
\text { appearance }\end{array}$ & 1 & 5 & 8.74 & 4.26 & $<0.00$ \\
\hline Do you have enough money & 1 & 5 & 9.56 & 4.22 & $<0.00$ \\
\hline $\begin{array}{l}\text { Do you find available } \\
\text { information }\end{array}$ & 1 & 5 & 10.01 & 4.05 & $<0.00$ \\
\hline $\begin{array}{l}\text { Do you have time for } \\
\text { leisure activities }\end{array}$ & 1 & 5 & 9.10 & 3.50 & $<0.00$ \\
\hline Are you able to get around & 1 & 5 & 11.88 & 4.40 & $<0.00$ \\
\hline Are you satisfied with sleep & I & 5 & 12.74 & 4.12 & $<0.00$ \\
\hline $\begin{array}{l}\text { Are you satisfied with your } \\
\text { ability to perform your daily } \\
\text { living activities }\end{array}$ & I & 5 & 12.20 & 3.80 & $<0.00$ \\
\hline $\begin{array}{l}\text { Are you satisfied with } \\
\text { ability to performance }\end{array}$ & 1 & 5 & 10.93 & 3.72 & $<0.00$ \\
\hline $\begin{array}{l}\text { Are you satisfied with your } \\
\text { personality }\end{array}$ & 1 & 5 & 11.54 & 3.66 & $<0.00$ \\
\hline $\begin{array}{l}\text { Are you satisfied with } \\
\text { your personal relationship }\end{array}$ & I & 5 & 13.67 & 3.44 & $<0.00$ \\
\hline $\begin{array}{l}\text { Are you satisfied with your } \\
\text { sex life }\end{array}$ & I & 5 & 8.05 & 4.14 & $<0.00$ \\
\hline $\begin{array}{l}\text { Are you satisfied with the } \\
\text { support you get }\end{array}$ & I & 5 & 14.98 & 2.70 & $<0.00$ \\
\hline $\begin{array}{l}\text { Are you satisfied with living } \\
\text { place }\end{array}$ & I & 5 & 14.78 & 2.74 & $<0.00$ \\
\hline $\begin{array}{l}\text { Are you satisfied with your } \\
\text { access to health service }\end{array}$ & I & 5 & 16.05 & 3.08 & $<0.00$ \\
\hline $\begin{array}{l}\text { Are you satisfied with your } \\
\text { transport access }\end{array}$ & 1 & 5 & 10.01 & 3.90 & $<0.00$ \\
\hline Have you negative feelings & 1 & 5 & 11.64 & 4.25 & $<0.00$ \\
\hline Physical health domain & 28 & 124 & 88.26 & 21.61 & $<0.00$ \\
\hline Psychological domain & 24 & 108 & 68.2 & 19.07 & $<0.00$ \\
\hline Social domain & 12 & 60 & 36.69 & 7.62 & $<0.00$ \\
\hline Environmental domain & 52 & 140 & 93.31 & 19.76 & $<0.00$ \\
\hline $\begin{array}{l}\text { Mean Global health quality } \\
\text { of life }\end{array}$ & 35 & 116 & 75.34 & 17.07 & $<0.00$ \\
\hline
\end{tabular}

Notes: Copyright $\odot 2004$ WHO. Adapted from WHO. The World Health Organization Quality of Life (WHOQOL)-BREF. Geneva: WHO; 2004:I-5. ${ }^{17}$ lack of money. The study conducted on breast cancer patient navigation in Ethiopia identified similar findings of delay seeking early treatment. ${ }^{22}$ Likewise, another study done on experience of initial symptoms of breast cancer and triggers for action in Ethiopia, identified that many women face significant delays for more than a year from noticing symptoms to accessing care through health care systems and with limited resources that increased the chances that their disease progressed significantly before initiating care. ${ }^{6}$

Among all participants $74.1 \%$ underwent breast surgery. This finding is in line with the that of a study conducted in Saudi Arabia (74\%). ${ }^{23}$ However, this finding is higher than findings of some studies conducted in Malaysia (68.4\%), Panama (65.3\%), and Ethiopia (68\% and 45.5\%). ${ }^{19,20,23-25}$ The most probable reasons for the variation of results could be the level of service, the duration and stage of breast cancer at which patients seek care. In this study, most dominating management of breast cancer is chemotherapy (89.2\%) which is consistent with the results of study conducted in Northern Ethiopia (96\%). ${ }^{20}$ Alternatively, it is very high from the findings of studies conducted in Malaysia (72\%), eastern China (47.4\%), Saudi Arabia (43.8\%), Sri Lanka (34.5\%), Turkey (16.4\%), and Iranian end-line finding (4.4\%). ${ }^{19,23,26-28}$ However, $29.5 \%$ of the patients had received radiotherapy which is lower than finding of a Saudi Arabian study. ${ }^{23}$ But it is at a better level in comparison to findings ofstudies in Turkey and northern Ethiopia where the service is not available at all. ${ }^{20,28}$ Only $3.5 \%$ had an earlier history of breast cancer. Previous history was excluded in Saudi Arabian and Australian studies. ${ }^{9,23}$ In contrasta Malaysian study found that $23.9 \%$ had a previous history of breast cancer. ${ }^{19}$ The probable reasons for the difference in results could the religious and cultural variation among breast cancer patients in different countries and regions.

The systemic literature review conducted in Africa, stated that many women delay seeking treatment for symptoms, with a large proportion of the diagnosed cancer until it becomes difficult for treatment because of lack of knowledge about cancer diagnosis and treatment, fear of surgery, preferences for alternative care, and challenges to receiving treatment. ${ }^{29,30}$ In this study nearly $50 \%$ of participants delayed medical care for more than six months related to painless symptom they practiced, seeking cultural and/or religious treatment even though they felt pain and due to lack of money. The guide to cancer early 
diagnosis clearly elaborated the above factors of delay in diagnosis and cancer treatment in general. ${ }^{30}$

This study focuses more on four domains and not on symptomatic assessment. As basic standard adopted from WHOQOL-BREF. ${ }^{17,18}$ The overall global health scale was $75.3(\mathrm{SD} \pm 17.1)$ with mean health satisfaction of 12.43 (SD \pm 3.98 ), that is in line with studies conducted in Sweden and Iran populations. ${ }^{31,32}$ However, it is inconsistent with studies conducted in different countries. . $^{19,25,26,28,34-37}$ The level of quality of care might vary among care providers and even among institutions where the care was provided. For instance, a study conducted in northern Ethiopia proved that there was no radiotherapy in its area during the study. This might be due to poor development of institutional capacity for management of cancer diseases in the country. Besides, there could be differences in standards of assessment tools used.

The current study revealed that among four domains of the WHOQOL-BREF the highest mean score was observed for environmental domain, followed by physical health domain. Whereas, the psychological and social domains were below the computed mean scale of global health quality of life. This may be due to the cultural view of the community and cancer stigma. ${ }^{30}$ Conversely, a Sri Lankan study identified that environmental and social domains had higher mean scores than physical and psychological domains. ${ }^{27}$ This could be one indication of variation of cultural, religious and social values, among different countries. Social environment is assumed vital to determine prognosis among breast cancer survivors as it is geared to alter basic physiological processes of patients. Low social environment in breast cancer patients shows increased risk for poor outcomes followed by delays in diagnosis. Inversely, exploitation of protective pathways activated through social engagement as novel therapeutic complements to contemporary treatments. ${ }^{37}$ Thus, low mean score of social domain is indicative of poor support or isolation of patients that may in turn lead to psychological problems. ${ }^{23}$ Since psychological domain is one of the predictors of quality of life, ${ }^{38}$ it might again be correlated with many aspects of life ${ }^{24}$ and psychological characteristics are associated with higher levels of health-related QOL impairment. ${ }^{39}$

Regarding individual questions, participants reported as they were very satisfied with the health service provided. This result is in agreement with the findings of studies conducted elsewhere. ${ }^{27,40}$ However, their need for medical treatment, feelings of their body appearance, enjoying luxurious activities and satisfaction with their sex life were predicted as very poor. This finding is in line with a Latvian study. ${ }^{40}$

\section{Conclusion and Recommendation}

Most prevalent domains reported in this study were environmental and physical domains. The social and psychological domains of study participants were very low in relation to reference value. Breast cancer patients in southern Ethiopia suffered from poor social and psychological support that in turn highly affected their life value and daily activities. Great attention should be given to enhance social and psychological support for breast cancer patients as a whole. Besides, a community-based longitudinal study is recommended to explore the reasons behind identified gaps.

\section{Abbreviations}

CMHS, College of Medicine and Health Science; ETB, Ethiopian birr; HUCSH, Hawassa University Comprehensive and Specialized Hospital; QOL, quality of life; WHOQOL-BREF, World Health Organization Quality of Life for breast cancer questionnaire.

\section{Ethics Approval and Informed Consent}

Ethical clearance was obtained from the Institutional Review Board at the College of Medicine and Health Sciences of Hawassa University. Permission was also be obtained from administrative bodies at HUCSH. Patients were enrolled into the study on a voluntary basis after a thorough explanation about the study. They were informed and we obtained verbal consent and interviewed during their visits to the cancer treatment center within 30 minutes. Any information obtained from the patients was kept anonymous.

\section{Acknowledgments}

We are grateful to the Hawassa University CMHS for technical and financial support. We would also like to thank staffs of oncology ward of HUCSH for their support during the data collection process.

\section{Author Contributions}

All authors made substantial contributions to conception and design, acquisition of data, or analysis and interpretation of data; took part in drafting the article or revising it critically for important intellectual content; gave final 
approval of the version to be published; and agree to be accountable for all aspects of the work.

\section{Disclosure}

All authors declare that there is no conflicts of interest in this work.

\section{References}

1. Fitzmaurice C, Allen C, Barber RM, et al.; Global Burden of Disease Cancer Collaboration. Global, regional, and national cancer incidence, mortality, years of life lost, years lived with disability, and disability-adjusted life-years for 29 cancer groups, 1990to 2016: a systematic analysis for the global burden of disease study. JAMAONCOL. 2018;4(11):1553-1568. doi:10.1001/jamaoncol.2018. 2706

2. Ginsburg O, Bray F, Coleman MP, et al. The global burden of women's cancers: a grand challenge in global health. Health, equity, and women's cancers. Lancet. 2016;389(10071):847-860. doi:10.10 16/S0140-6736(16)31392-7

3. Memirie ST, Habtemariam MK, Asefa M, Estimates of cancer incidence in Ethiopia in 2015 using population-based registry data. Journal of Global Oncology. 2018;4:1-11. doi:10.1200/JGO.17.00 175

4. Timotewos G, Solomon A, Mathewos A, et al. First data from a population based cancer registry in Ethiopia. Cancer Epidemiol. 2018;53:93-98. doi:10.1016/j.canep.2018.01.008

5. Woldeamanuel YW, Girma B, Teklu AM. Cancer in Ethiopia. Lancet Oncol. 2013;14(4):289-290. doi:10.1016/S1470-2045(12)70399-6

6. Dye TD, Bogale S, Hobden C, Tilahun Y, Deressa T, Reeler A. Experience of initial symptoms of breast cancer and triggers for action in Ethiopia. Int $J$ Breast Cancer. 2012;2012:1-5. doi:10. $1155 / 2012 / 908547$

7. Erku DA. Complementary and alternative medicine use and its association with quality of life among cancer patients receiving chemotherapy in Ethiopia: a cross-sectional study. Evidence Based Complementary Altern Med. 2016;2016.

8. Partridge AH. Cancer Survivorship and the Young Breast Cancer Patient: Addressing the Important Issues. AlphaMed Press; 2013.

9. Sipio TD Health-related quality of life among breast cancer survivors: Town and country experiences Queensland University of Technology; 2009.

10. Mogens G Health-related quality of life in early breast cancer [doctoral thesis]. Danish Medical Bulletin: University of Copenhagen; 2010

11. Lehto US, Ojanen M, Kellokumpu-Lehtinen P. Predictors of quality of life in newly diagnosed melanoma and breast cancer patients. Ann Oncol. 2005;16(5):805-816. doi:10.1093/annonc/mdi146

12. Dvaladze ALE. Living with Breast Cancer: Experiences and Perceptions of Women in Georgia. University of Washington; 2012.

13. Opitz T, Azé J, Bringay S. Breast Cancer and Quality of Life: Medical Information Extraction from Health Forums. Istanbul, Turkey: Medical Informatics Europe; 2014.

14. Donna B, Jeffe MP, Emily F, Liu Y, Schootman M. The effects of surgery type and chemotherapy on early-stage breast cancer patients' quality of life over 2-year follow-up. Ann Surg Oncol. 2016;23 (3):735-743. doi:10.1245/s10434-015-4926-0

15. Ethiopia FMoH.NATIONAL CANCER CONTROL PLAN 20162020. In: Addis Ababa DISEASE PREVENTION AND CONTROL DIRECTORATE, editor. DIRECTORATE DPAC; 2015.

16. Reeler AV, Sikora K, Solomon B. Overcoming challenges of cancer treatment programmes in developing countries: a sustainable breast cancer initiative in Ethiopia. Clin Oncol. 2008;20(2):191-198. doi:10.1016/j.clon.2007.11.012
17. WHO. The World Health Organization Quality of Life (WHOQOL)BREF. Geneva: WHO; 2004:1-5.

18. Vahed S. World Health Organization Quality-of-Life Scale (WHOQOL-BREF): analyses of their item response theory properties based on the graded responses model. Iran J Psychiatry. 2010;5 (4):140-153.

19. Kumarasamy Z, Kumarasamy V. Quality of life among female breast cancer patients in a university hospital in Malaysia. $\mathrm{Br} J$ Med Med Res. 2015;6(5):453-462. doi:10.9734/BJMMR/2015/15065

20. Deressa BT, Cihoric N, Badra EV, Tsikkinis A, Rauch D. Breast cancer care in northern Ethiopia -cross-sectional analysis. $B M C$ Cancer. 2019;19(393):1-6. doi:10.1186/s12885-019-5612-6

21. Ersumo T. Breast cancer in an Ethiopian population, Addis Ababa. East Cent Afr J Sur. 2006;11(1):81-86.

22. Dye TD, Bogale S, Hobden C, et al. Complex care systems in developing countries: breast cancer patient navigation in Ethiopia. Cancer. 2010;116(3):577-585. doi:10.1002/cncr.24776

23. Al Zahrani AM, Alalawi Y, Yagoub U. Quality of life of women with breast cancer undergoing treatment and follow-up at king salman armed forces hospital in Tabuk, Saudi Arabia. Breast Cancer. 2019;2019(11):199-208.

24. Castro M. Quality of Life in Female Breast Cancer Survivor in Panama. University of South Florida; 2013.

25. Abegaz TM, Ayele AA, Gebresillassie BM. Health related quality of life of cancer patients in Ethiopia. Hindawi J Oncol. 2018;2018:1-9. doi:10.1155/2018/1467595

26. Qing Chen SL, Wang M, Liu L, Chen G. Health-related quality of life among women breast cancer patients in Eastern China. Biomed Res Int. 2018;2018:12.

27. Munasinghe WHNP, Rathnayaka N. Quality of life and satisfaction with care among breast cancer survivors receiving different treatments strategies in Sri Lanka. Cancer Ther Oncol Int J. 2016;2(1).

28. Sehsuvar Gokgoz GS, Paksoy E, Guneytepe U, Ozcakir A. Nuran Bayram, and Nazan Bilgel. Health related quality of life among breast cancer patients: a study from Turkey. Glob J Health Sci. 2011;3:2.

29. Brinton LA, Figueroa JD, Awuah B, et al. Breast cancer in SubSaharan Africa: opportunities for prevention. Breast Cancer Res Treat. 2014;144(3):467-478. doi:10.1007/s10549-014-2868-z

30. WHO. Guide to Cancer Early Diagnosis. Geneva: Creative Commons Attribution-NonCommercial-ShareAlike; 2017.

31. Michelson H, Bolund C, Nilsson B, Brandberg Y. Health-related quality of life measured by the EORTC QLQ-C30: reference values from a large sample of the Swedish population. Acta Oncol (Madr). 2000;39(4):477-484. doi:10.1080/028418600750013384

32. Montazeri A, Vahdaninia M, Harirchi I, et al. Quality of life in patients with breast cancer before and after diagnosis: an eighteen months follow-up study. BMC Cancer. 2008;8(330):1-6. doi:10.11 86/1471-2407-8-330

33. Safaee A, Moghimi-Dehkordi B, Zeighami B, Tabatabaee HR, Pourhoseingholi MA. Pourhoseingholi Predictors of quality of life in breast cancer patients under chemotherapy. Indian $J$ Cancer. 2008;45(3):3. doi:10.4103/0019-509X.44066

34. Pinar R, Salepci T, Afsar F. Assessment of quality of life in Turkish patients with cancer. Turk j Cancer. 2003;33(2):96-101.

35. Sibhat SG, Fenta TG, Sander B, Gebretekle GB. Health-related quality of life and its predictors among patients with breast cancer at Tikur Anbessa specialized hospital, Addis Ababa. Ethiop Health Qual Life Outcomes. 2019;17(165):1-10.

36. Hassen AM, Taye G, Gizaw M, Hussien FM. Quality of life and associated factors among patients with breast cancer under chemotherapy at Tikur Anbessa specialized hospital, Addis Ababa. Ethiop PLoS ONE. 2019;14:9.

37. Adam Hinzey MMG-D, Maryam B, Lustberg A. Courtney DeVries. Breast Breast cancer and social environment: getting by with a little help from our friends. Breast Cancer Res. 2016;18(1):54. 
38. Carbine NELL, Wallace J, Ko H. Risk-reducing mastectomy for the prevention of primary breast cancer (Review). Cochrane Database Syst Rev. 2018;2018(4):164.

39. Cornish D, Holterhues C, Van de Poll-franse LV, Coebergh JW, Nijsten T. A systematic review of health-related quality of life in cutaneous melanoma. Ann Oncol. 2009;20(6):1-8. doi:10.1093/ annonc/mdp255
40. Pranka M, Dzervite A, Rungule R Assessment of life quality factors by breast cancer patients. SHSWeb of Conferences: EDP Sciences; 2014. p. $1-10$.

Breast Cancer: Targets and Therapy

\section{Publish your work in this journal}

Breast Cancer - Targets and Therapy is an international, peer-reviewed open access journal focusing on breast cancer research, identification of therapeutic targets and the optimal use of preventative and integrated treatment interventions to achieve improved outcomes, enhanced survival and quality of life for the cancer patient.
The manuscript management system is completely online and includes a very quick and fair peer-review system, which is all easy to use. Visit http://www.dovepress.com/testimonials.php to read real quotes from published authors. 